\title{
PEMETAAN SARANA DAN PRASARANA OBJEK PARIWISATA DI KABUPATEN SEMARANG JAWA TENGAH MENGGUNAKAN SISTEM INFORMASI GEOGRAFI
}

(Facilities and Infrastructure Mapping of Tourism Attractions in Semarang Regency Central Java using Geographic Information System)

Febrian Wahyu Christanto, Susanto

Fakultas Teknologi Informasi dan Komunikasi Universitas Semarang

\begin{abstract}
One of the benefits of Geographic Information System is to introduce an area on the surface of the earth in the form of digital map. This system aims to transform traditional map to an integrated system and the information required by the user. Referring to the usefulness of this Geographic Information System, this research purposes to create a geographic information system for tourism attractions in Semarang regency and to introduce further about tourism attractions in the area. By using technology, internet and other applications supports, this system is expected to work well accordingly, and to introduce all tourism attractions in Semarang regency.
\end{abstract}

Keywords : geographic information system,tourism

\section{PENDAHULUAN}

Kabupaten Semarang adalah suatu wilayah teritorial di propinsi Jawa Tengah yang sangat strategis karena sangat dekat dengan ibukota Jawa Tengah yaitu Semarang. Perjalanan dari Kabupaten ini menuju ke Semarang dapat ditempuh melalui perjalanan darat selama lebih kurang dua puluh menit. Daerah ini merupakan salah satu kabupaten terbesar yang berada di wilayah propinsi Jawa Tengah [1]. Dengan kondisi geografi luas yang terdapat di lereng gunung Ungaran dan gunung Merbabu maka tentu saja akan banyak sekali objek pariwisata yang akan timbul karena kenampakan alam pegunungan yang memang potensial untuk dijadikan suatu daerah tempat wisata dan sebagai sumber perekonomian masyarakat pula.

Terhitung sampai tahun 2011 ini objek wisata yang berada di wilayah kabupaten Semarang adalah sekitar dua puluh objek dengan berbagai fasilitasnya[2]. Terdapat beberapa objek andalan di kawasan ini yang terkenal diantara para wisatawan domestik maupun asing. Objek ini diantaranya adalah Candi Gedong Songo, Goa Maria Ambarawa, Kampung Kopi Banaran, dan masih banyak lagi objek yang berada di kawasan Kabupaten Semarang yang sangat baik dikenalkan ke khalayak umum sebagai daerah wisata. Selain itu juga terdapat objek-objek baru yang dapat dikenalkan kepada para wisatawan karena potensinya yang menarik. Dengan banyaknya objek wisata yang belum dikenal oleh wisatawan khususnya dari luar kota maupun wisatawan mancanegara, maka dibutuhkan suatu media untuk memperkenalkan objekobjek yang belum terkenal ini.

Dalam dunia maju saat ini peran teknologi sangat dibutuhkan untuk memperkecil batasan jarak dan batasan waktu di belahan dunia manapun. Website adalah salah satu teknologi 
di dunia sistem informasi yang sangat terkenal saat ini dengan merambahnya dunia internet yang marak saat ini. Banyak sekali jenis website yang timbul antara lain sistem informasi yang juga beraneka macam seperti sistem informasi geografi, sistem informasi akuntansi, sistem informasi akademik, dan sebagainya. Sistem informasi geografi dipilih sebagai subjek penelitian ini karena kegunaannya yang sangat sesuai untuk memperkenalkan seluruh daerah wisata Kabupaten Semarang beserta beberapa fasilitasnya ke khalayak umum agar dapat dikunjungi dan dinikmati oleh para wisatawan. Dalam sistem informasi geografi ini adalah visualisasi dari sebuah peta fisik seperti atlas maupun globe menjadi sebuah peta digital yang disatukan dengan suatu sistem agar peta tersebut terdapat informasi yang lengkap yang nantinya dibutuhkan untuk wisatawan dalam menentukan tujuan wisatanya.

Dengan adanya Sistem Informasi Geografi Kabupaten Semarang berbasis website dan dukungan teknologi internet diharapkan akan lebih memperkenalkan kawasan Kabupaten Semarang ke luar terutama dalam hal pariwisata yang ditawarkan karena sebagian pendapatan daerah di kabupaten ini dan masyarakatnya adalah dari sektor pariwisata. Penelitian ini diharapkan pula dapat digunakan sebagai kepada Pemerintah Daerah Kabupaten Semarang untuk memajukan daerahnya serta dan menjadi tolok ukur untuk penelitian-penelitian selanjutnya.

\section{TINJAUAN PUSTAKA}

Menurut arti kata Pariwisata atau turisme adalah suatu perjalanan yang dilakukan untuk rekreasi atau liburan, dan juga persiapan yang dilakukan untuk aktivitas ini. Sedangkan wisatawan adalah seseorang yang melakukan perjalanan paling tidak sejauh $80 \mathrm{~km}$ (50 mil) dari rumahnya dengan tujuan rekreasi, merupakan definisi oleh Organisasi Pariwisata Dunia. Dan Industri pariwisata adalah kumpulan usaha pariwisata yang saling terkait menghasilkan barang dan atau jasa bagi pemenuhan kebutuhan wisatawan pada penyelenggaraan pariwisata [3]

Sebelum penelitian ini dilakukan telah terdapat beberapa penelitian tentang sistem informasi geografi pariwisata antara lain adalah penelitian berjudul Perancangan dan Implementasi Web GIS Pariwisata Kabupaten Sumba Timur yang memetakan daerah-daerah wisata yang berada di wilayah Kabupaten Sumba Timur. Di dalam penelitian ini digambarkan peta daerah Sumba Timur dan beberapa daerah wisata yang berada dalam kawasan tersebut beserta beberapa informasi yang menyertainya [4].

Dalam penelitian lainnya yang berjudul Pemanfaatan Penginderaan Jauh dan Sistem Informasi Geografis Untuk Mendukung Inventarisasi dan Pengelolaan Sumberdaya Wilayah Pesisir Di Kabupaten Gresik Dengan Pendekatan Survei Cepat Terintegrasi digambarkan pemanfaatan sistem informasi geografi untuk membantu inventarisasi dan pengelolaan sumber daya kelautan di wilayah pesisir Kabupaten Gresik yang tentu saja untuk membantu pemerintahan setempat dalam meningkatkan taraf perekonomian rakyat Gresik [5]. Penelitian terdahulu lainnya mengambil judul Sistem Informasi Geografi Untuk Perjalanan Wisata di Kota Semarang hampir sama dengan penelitian ini yaitu memetakan daerah-daerah wisata beserta informasinya yang berada di wilayah Kotamadya Semarang Jawa Tengah [6].

Pada penelitian ini lebih ditekankan untuk memperkenalkan seluruh lokasi pariwisata yang berada di kawasan Kabupaten Semarang. Tujuan dari pembuatan sistem informasi geografi untuk pariwisata Kabupaten Semarang ini adalah untuk memperkenalkan objek-objek wisata potensial bagi wisatawan yang belum mengenal Kabupaten Semarang.

\section{Sistem Informasi Geografis}

Sistem Informasi Geografi (SIG) pada dasarnya merupakan gabungan dari tiga unsur pokok yaitu sistem, informasi, dan geografis. SIG merupakan suatu sistem informasi yang menekankan pada unsur "informasi geografi". 
Istilah informasi geografis mengandung pengertian mengenai tempat-tempat yang terletak di permukaan bumi, pengetahuan mengenai posisi dimana suatu objek terletak di permukaan bumi, dan informasi mengenai keterangan-keterangan (atribut) yang terdapat di permukaan bumi yang posisinya diberikan atau diketahui.

Sistem Informasi

Geografis menghubungkan kumpulan dari unsur-unsur yang terdapat di dalam peta dengan atributatributnya ke dalam sebuah satuan yang disebut dengan layer. Layer berupa batasbatas administrasi kabupaten/kota dan kecamatan. Sistem Informasi yang dirancang akan menghubungkan beberapa layer tersebut beserta atributnya sehingga membentuk sebuah basisdata. Sistem juga melakukan analisis spasial sehingga dapat memberikan informasi yang dibutuhkan oleh pengguna.

Sejak pertengahan 1970-an, dikembangkan sistem-sistem yang secara khusus dibuat menangani masalah informasi yang bereferensi geografis dalam berbagai cara dan bentuk. Masalah mencakup pengorganisasian data dan informasi, menempatkan informasi pada lokasi tertentu, dan melakukan komputasi, memberikan ilustrasi keterhubungan satu sama lainnya, beserta analisa-analisa spasial lainnya.

Sebutan umum bagi sistem-sistem yang menangani masalah-masalah itu adalah sistem informasi geografis. SIG membantu manusia memahami dunia nyata dengan melakukan proses-proses manipulasi dan presentasi data yang direalisasikan dengan lokasi-lokasi geografis di permukaan bumi [7].
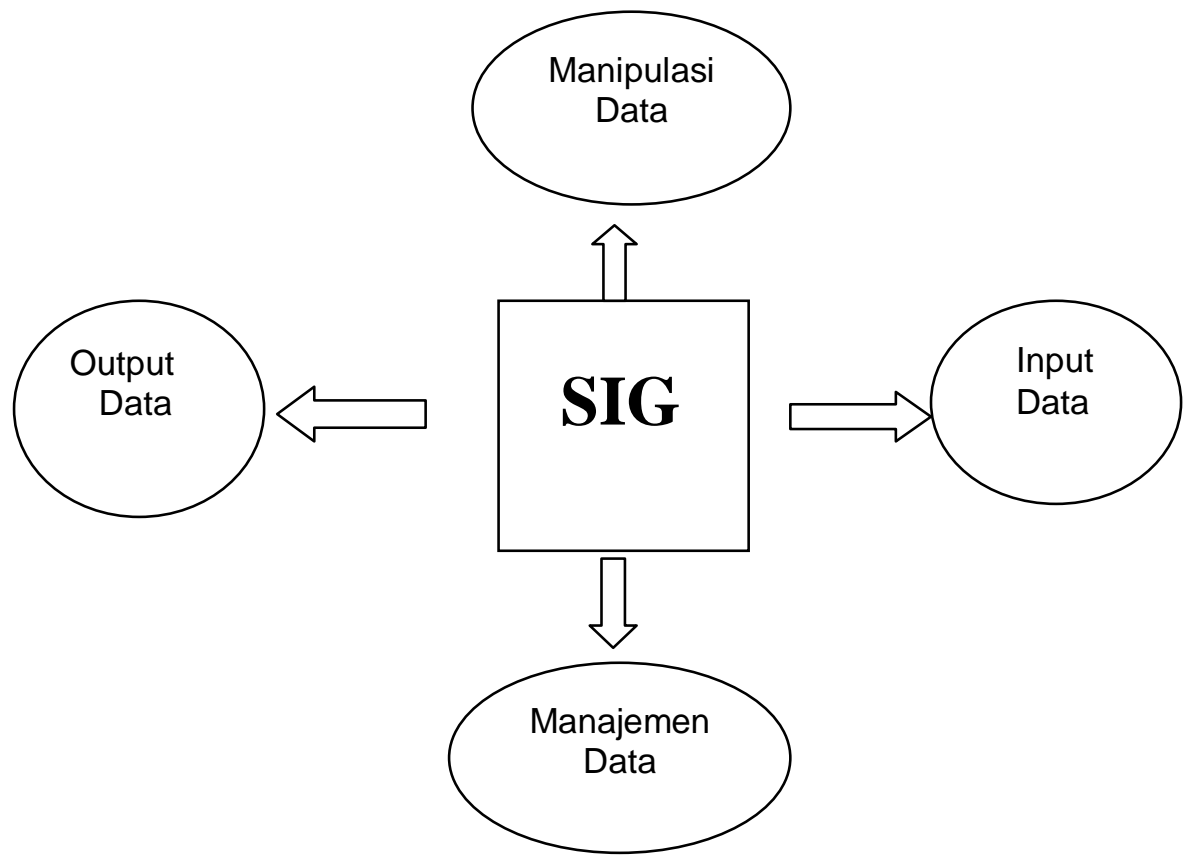

Gambar 1. Subsistem-subsistem SIG [7]

Pada sistem informasi geografis terdapat beberapa subsistem yang masing-masing subsistem memiliki fungsi spesifik yaitu input data yaitu subsistem yang bertugas untuk mengelola masukkan-masukkan data spasial yang ada, output data yaitu pada subsistem ini informasi baik berbentuk peta, tabel, maupun laporan ditampilkan, manajemen data yaitu subsistem yang mengorganisasi data spasial maupun atribut ke dalam basisdata, dan manipulasi data yaitu subsistem yang berfungsi untuk menentukan informasiinformasi apa saja yang dihasilkan dan ditampilkan. Selain itu subsistem ini bertugas untuk manipulasi dan permodelan data sehingga menjadi informasi yang diharapkan. 


\section{PERANCANGAN SISTEM}

Sebelum aplikasi dibuat ada baiknya melalui proses perancangan suatu aplikasi agar aplikasi yang tebuat nantinya dapat beguna sesuai dengan rencana dan dijalankan dengan tepat guna. Dalam penelitian ini perancangan aplikasi menggunakan Data Flow Diagram (DFD) untu mempermudah pembuat aplikasi dalam membuat sistem informasi geografis nantinya.

Data Flow Diagram adalah tekik grafis yang digunakan untuk menggambarkan aliran informasi dan tranformasi data yang terdapat di dalam sistem. DFD sering juga disebut juga diagram aliran data. DFD dapat didekomposisikan (dipartisi) ke dalam beberapa tingkatan yang merepresentasikan aliran-aliran data dan informasi berikut detildetil fungsionalnya. Pembuatan Data Flow Diagram terbagi menjadi beberapa tahapan. Melalui tahap-tahap ini akan dihasilkan penyaringan sesuai dari data pada saat data bergerak melalui proses yang membentuk aplikasi [8].

Permintaan Data
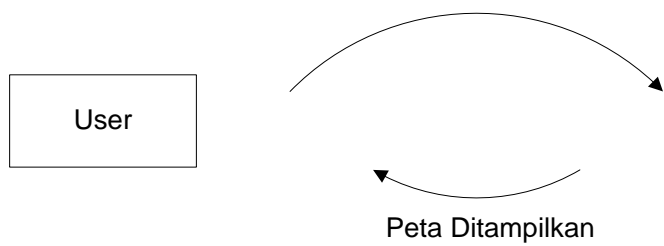

Gambar 2. DFD Level 0
Sistem Informasi

Geografi Pariwisata

Kabupaten Semarang

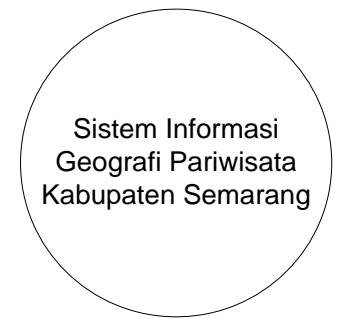

Gambar 2 menjelaskan DFD Level 0 informasi yang diinginkan yang tentu saja aplikasi Sistem Informasi Geografis Pariwisata Kabupaten Semarang. Dalam aplikasi ini yang bertindak sebagai actor adalah hanya user yang mengakses sistem untuk mendapatkan

berurusan dengan daerah pariwisata di Kabupaten Semarang. Sedangkan untuk DFD Level 1 digambarkan pada Gambar 3.

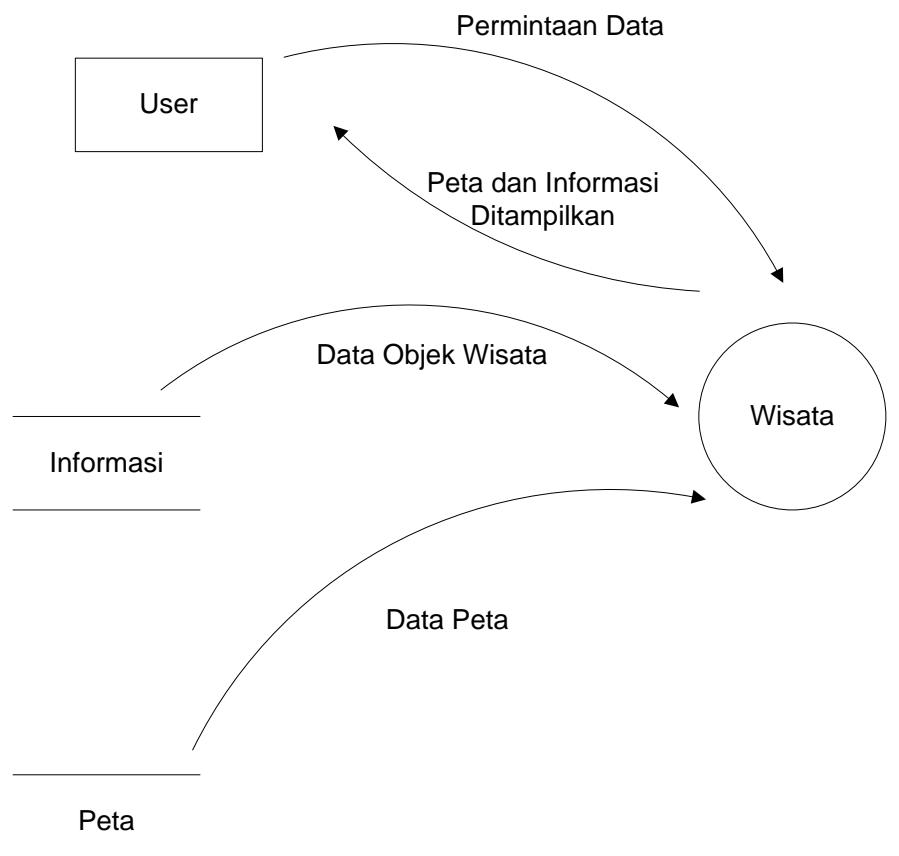

Gambar 3. DFD Level 1 
Dalam Gambar 3 dijelaskan DFD Level 1 aplikasi dimana aliran data lebih detil di diagram ini. Dalam Gambar 3 dijelaskan user akan mengakses sistem untuk mengambil data pariwisata, sedangkan sistem akan mengambil data tersebut dari peta digital dan informasiinformasi pendukung yang sudah tersimpan di dalam basisdata.

Sedangkan untuk perancangan basisdata dalam sistem ini dibutuhkan satu tabel saja untuk menyimpan informasi nama kecamatan dan objek wisata agar peta yang ditampilkan dapat disertai dengan beberapa informasi sehingga memperjelas dan mempermudah pengguna nantinya dalam memperoleh informasi tentang daerah wisata Kabupaten Semarang. Rancangan basisdata terdapat di dalam Tabel 1.

Tabel 1. Tabel Basisdata SIG Pariwisata Kabupaten Semarang

\begin{tabular}{|l|l|c|}
\hline No & \multicolumn{1}{|c|}{ Nama Field } & Tipe data \\
\hline 1. & Nama Kecamatan & String \\
\hline 2. & Objek Wisata & String \\
\hline
\end{tabular}

Dalam Tabel 1 dijelaskan terdapat dua field untuk menyimpan beberapa informasi dan foto dari objek-objek yang berada di dalam peta untuk mendukung sistem informasi geografis yang akan dibangun. Objek wisata dalam sistem ini dipisahkan berdasarkan kecamatan dimana suatu objek berada, sehingga dibutuhkan field Nama Kecamatan dalam tabel basisdata, sedangkan untuk field Objek Wisata adalah untuk menyimpan file text sebagai informasi suatu objek disertai beberapa foto.

\section{IMPLEMENTASI DAN ANALISA HASIL}

Setelah proses perancangan dilakukan kemudian masuk ke dalam proses implementasi aplikasi. Aplikasi ini dibangun dengan bahasa pemrograman PHP dengan Code Igniter sebagai framework. Aplikasi ini didukung oleh aplikasi pembuat peta yaitu Arc View GIS untuk tampilan petanya sehingga sistem akan menjadi suatu sistem besar yang handal, menarik, serta memberikan informasi yang dibutuhkan bagi penggunanya.

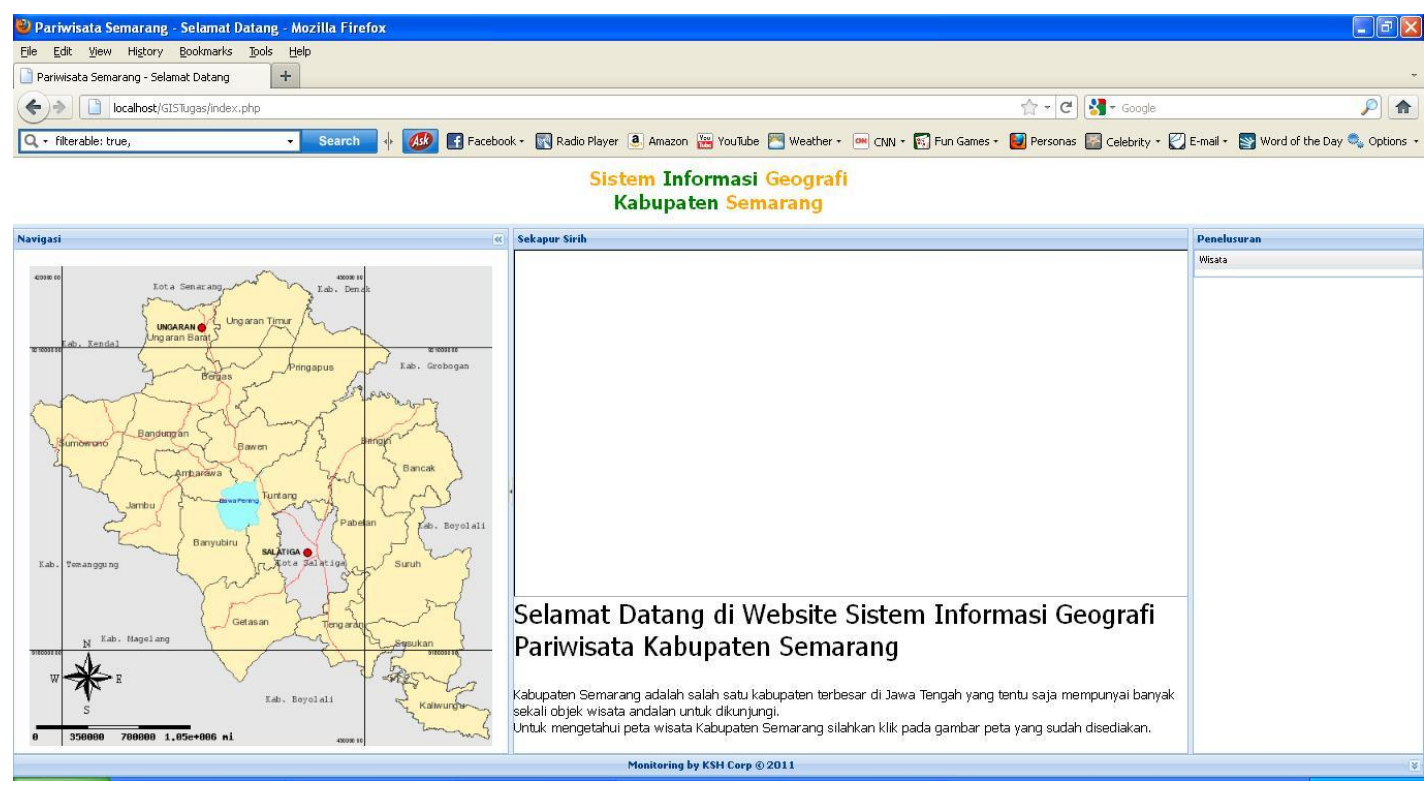

Gambar 4. Halaman Index Aplikasi 
Pada Gambar 4 dijelaskan gambaran halaman index sistem informasi geografis yang berupa peta wilayah dari Kabupaten Semarang. Dalam halaman ini tergambar peta detail berekstensi .shp dari wilayah Kabupaten Semarang yang di dalamnya terdapat suatu wilayah kota yaitu Salatiga. Selain peta, halaman ini juga dilengkapi dengan pengenalan akan daerah Kabupaten Semarang dan dengan desain berwarna natural sehingga pemakai tidak akan lelah mata dalam mengakses halaman demi halaman sistem informasi geografi ini. Halaman ini akan berubah apabila salah satu kecamatan dipilih menggunakan klick peta. Maka akan muncul beberapa daerah wisata yang berada dalam kawasan kecamatan tersebut. Gambar tersebut tergambar dalam Gambar 5.

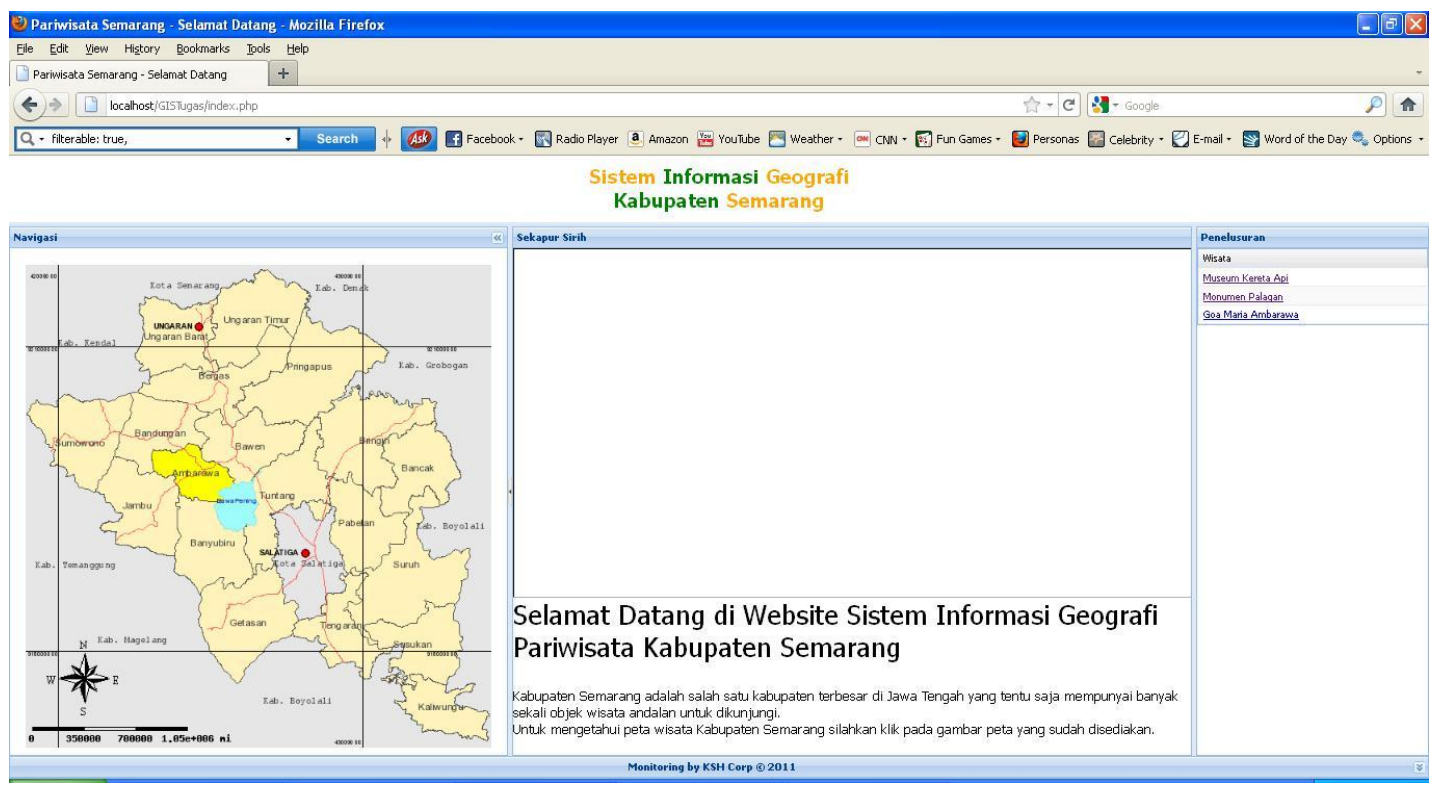

Gambar 5. Halaman Penentuan Wilayah

Dalam Gambar 5 dijelaskan setelah peta ditentukan maka akan muncul beberapa link objek pariwisata yang berada di tempat yang dipilih tersebut. Untuk pembagian daerah wisata dilakukan berdasarkan wilayah kecamatan yang pada tiap kecamatan mempunyai beberapa objek wisata sesuai dengan kenampakannya di alam nyata. Apabila nantinya ditekan link tersebut maka akan muncul informasi tentang objek seperti letak, legenda, fasilitas, foto, dan sebagainya. Untuk informasi objek yang dipilih oleh pengguna maka apabila ditekan link objek yang sudah disediakan akan muncul halaman informasi objek di tempat yang sudah disediakan yaitu di tengah halaman utama. Untuk penggambaran halaman ini terdapat dalam Gambar 6. 


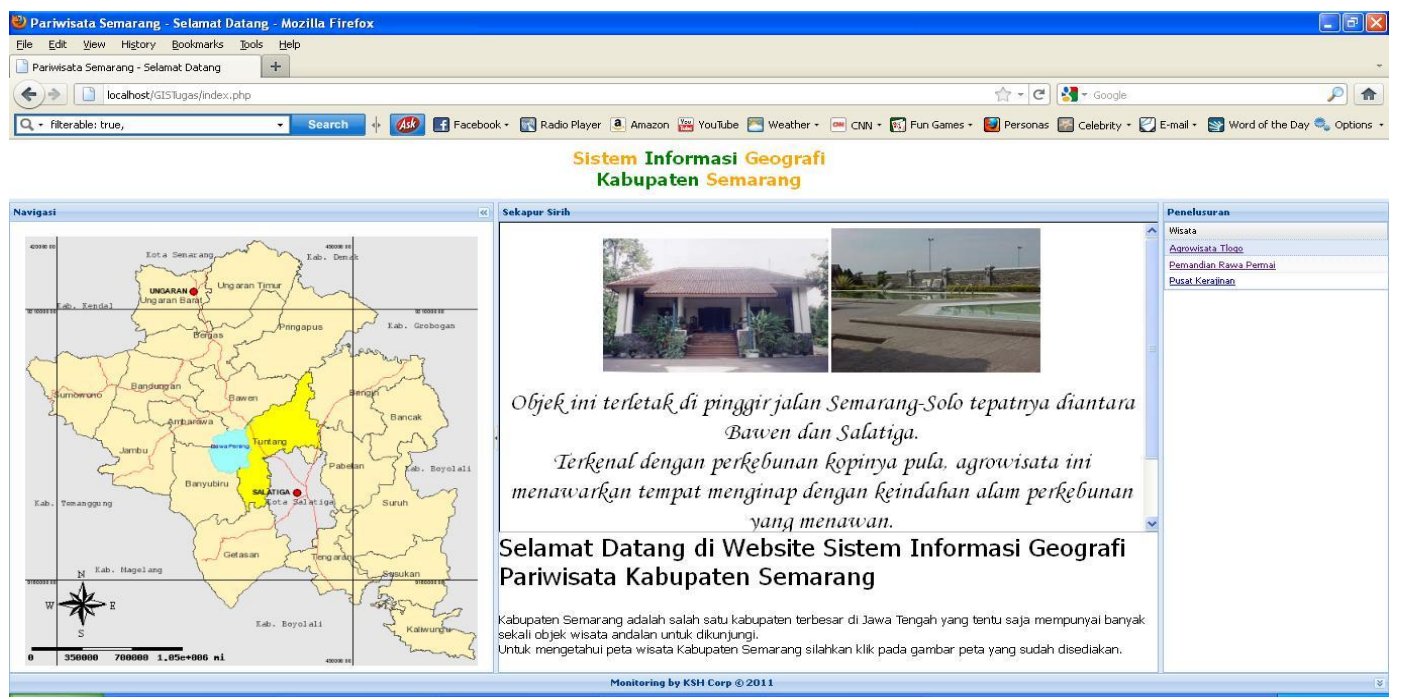

Gambar 6. Halaman Informasi Objek

Sedangkan pada Gambar 6 dijelaskan informasi objek pariwisata yang telah digunakan pengguna beserta foto sehingga mempermudah pengguna dalam proses memahami dan mengenali daerah wisata yang ingin dituju. Ekstensi file objek yang dituju cukup sederhana karena hanya menggunakan $. h t m /$ dan disertai beberapa foto.

\section{KESIMPULAN}

Sistem Informasi Geografis Pariwisata di Kabupaten Semarang yang nantinya dibangun akan mampu memberikan informasi dan mengenalkan seluruh objek pariwisata yang berada di daerah Kabupaten Semarang. Sistem Informasi Geografis Pariwisata Kabupaten Semarang akan menambah lebih powerful dan informatifnya Website Resmi Pemerintah Kabupaten Semarang (http://www.semarangkab.go.id) apabila nantinya dipadukan menjadi suatu kesatuan sistem

Informasi yang disajikan berupa peta digital dipadu dengan teknologi website dengan beberapa informasi yang menarik disertai dokumentasi lokasi-lokasi pariwisata di Kabupaten Semarang diharapkan mampu memudahkan pengguna dalam mengenali objek wisata yang ingin dituju. Aplikasi ini pun diharapkan pula dapat membantu Pemerintah Daerah Kabupaten Semarang untuk lebih memperkenalkan sektor pariwisata di daerahnya kepada khalayak umum.

Dengan sistem informasi yang nantinya dibangun ini dapat dikembangkan lagi ke depan menuju arah yang lebih besar kemungkinan untuk informasi penginapan, pengisian bahan bakar, tempat makan, ataupun penentuan jarak terpendek menuju lokasi. Akhirnya penulis mengharapkan agar aplikasi ini dapat pula digunakan oleh Pemerintah Daerah Kabupaten Semarang ataupun digunakan sebagai acuan penelitian berikutnya.

\section{DAFTAR PUSTAKA}

[1] Central Java Passion Strength Heritage. http://www.jatengprov.go.id (diakses tanggal 2 Desember 2011).

[2] Portal Informasi Pemerintah Kabupaten Semarang. http://www.semarangkab.go.id (diakses tanggal 2 Desember 2011).

[3] Ismayanti. 2009. Pengantar Pariwisata. Jakarta : Grasindo

[4] Tanaamah, Andeka Rocky. 2008. Perancangan dan Implementasi Webgis Pariwisata Kabupaten Sumba Timur. Surabaya : Jurnal Informatika Vol. 9 Universitas Kristen Petra. 
[5] Murti, Sigit Heru. 2004. Pemanfaatan

Penginderaan Jauh dan Sistem Informasi Geografis Untuk Mendukung Inventarisasi dan Pengelolaan Sumberdaya Wilayah Pesisir Di Kabupaten Gresik Dengan Pendekatan Survei Cepat Terintegrasi. Yogyakarta : Universitas Gajah Mada.

[6] Manongga, Dany, Samuel Papilaya, Selfiana Pandie. 2009. Sistem Informasi Geografi Untuk Perjalanan Wisata di Kota Semarang. Surabaya : Jurnal Informatika Vol. 10 Universitas Kristen Petra.

[7] Prahasta, Eddy. 2001. Konsep-konsep Dasar Sistem Informasi Geografis. Bandung : Informatika.

[8] Pressman, R.S. 1997. Software Engineering: A Practitioner's Approach. New York: The McGraw-Hill Companies Inc. 